Teaching and assessment for an organisation centred curriculum

\title{
Sarojni CHOY
}

Faculty of Education, Queensland University of Technology, s.choy@qut.edu.au 


\title{
Teaching and assessment for an organisation centred curriculum
}

\begin{abstract}
Purpose - This paper discusses the teaching and assessment strategies for an organisation centred curriculum. Design/methodology/approach - The paper is based on a case study. Data was collected from interviews and a focus group with worker-learners enrolled in a Graduate Certificate in Education (Educational Leadership) course.
\end{abstract}

Findings - A project that piloted an organisation centred curriculum framework where learning was integrated in the context of the workplace, met the needs of both, individuals and their workplace. The success of such learning for a cohort of worker-learners was contingent on especially designed teaching and assessment strategies, aligned learning and assessment to the strategic goals of the organisation where the cohort was based and to needs of the individuals. The evaluation of the strategies in the framework shows their potential to optimise learning outcomes for other cohorts and courses. It also highlights the importance of skilling learners for work integrated learning and making explicit the pedagogies and affordances available in the workplace.

Originality/value - Demonstrates the transition from university centred to organisation centred curriculum that employs work integrated learning to meet the needs of the workplace and the learners.

Key words Work integrated learning, Work-based learning, Assessment, Organisational centred curriculum, Workforce capacity building

Paper type Case study

\section{Introduction}

Organisations that sponsor staff to undertake academic studies, in order to build their workforce capacity, expect learning experiences and outcomes to be aligned with their business. Such expectations present challenges for academics when designing, facilitating and assessing learning. This is not unusual, as explained by Boud and Symes (2000): "When learning challenges are created from the exigencies of work there is often no pre-existing map that represents the territory of knowledge being explored" (p.20). The origins of knowledge and their boundaries in a work based learning context are a lot more nebulous compared to fixed disciplines of academia. Despite recent research on learning in the workplace, the development of rigorous pedagogy to underpin work based learning, particularly assessment, is still in its infancy (Brodie and Irving, 2007).

This paper is based on a case study that developed and piloted an organisation centred curriculum (OCC) framework to develop leadership capacity of twelve worker-learners through a Graduate Certificate in Education (Executive Leadership) course. This framework suited both the organisation and the worker-learners. The paper begins with an overview of the OCC framework and goes on to describe the teaching and assessment strategies applied by the author. It then discusses the findings of an evaluation of the teaching and assessment approaches. In concluding the paper, the author draws on the evaluation data and her reflective notes to suggest potential for use of the teaching and assessment strategies, for worker-learner cohorts participating in other work-based learning courses.

\section{Overview of Organisation Centred Curriculum Framework}

The rationale for an OCC framework originated from preliminary discussions with a non-government organisation (NGO) seeking leadership capacity building of twelve staff. The NGO has responsibility for implementing reforms in the health and community services industry in the state of Queensland, Australia. Details for the curriculum content and delivery approaches were negotiated during the needs analysis phase. The OCC framework was founded on agreement around three principles:

- a partnership between the university and the NGO; 
- the learning activities be based on the needs of the NGO and the worker-learners, hence linked to work projects (technically, learning was work-integrated); and

- assessment and evaluation against agreed standards and measures for work outcomes and academic learning objectives of each of the four study units.

Boud and Solomon (2001) strongly recommend this type of arrangement for successful work-based learning. Rhodes and Shiel (2007) describe work based learning as: “... where students are full-time employees whose programme of study is embedded in the workplace and is designed to meet the learning needs of the employees and the aims of the organization.” (p.174). Sobiechowska and Maisch (2006) also share similar interpretations. In this paper the term work integrated learning is used to echo these definitions of work based learning. The study program in this case was a moderately tailored version of an existing university course. The NGO was interested in work integrated learning that would develop the leadership capacity of twelve staff and help them implement reforms recently introduced by the state government.

Various arguments (eg. by Billett, 2001; Brown, 1998; Symes and McIntyre, 2000; Billett and Boud, 2001; Bryson, Pajo, Ward and Mallon, 2006) in favour of the workplace as an effective learning environment provided justification for embedding the leadership development program within the context of the NGO. The OCC framework was founded on the organisation's strategic goal, philosophies and culture to simultaneously meet the needs of the individuals and their organisation. The strategic goal of the NGO was to:

Contribute to the quality of life and community well-being of Queenslanders by creating alliances, collaboration and connections that enhance credibility; being a voice to influence government, industry, work and training policy; and creating opportunities for community skilling through developing the capacity and quality of our workforces.

Accordingly, the strategic goal of the organisation was positioned at the core of the framework, surrounded by its philosophies and culture. Organisational culture is usually described as the taken-forgranted values, underlying assumptions, expectations, collective memories and definitions present in an organisation (Cameron and Quinn, 1999). These elements impact on how new ideas are viewed in an organisation and also influence their interpretation for practice. At the next level, the university learning units surrounded these structures (organisational goal, philosophies and culture). The teaching and assessment strategies were designed to influence changes that traverse through the organisation and its environmental cultures, at the same time respect its philosophies and values. Strategically, the curriculum design focused on outcomes that led to the achievement of the organisation's strategic goals, yet maintained the academic standard and quality.

Work integrated learning in this instance hinged on interactions between the disciplinary area, professional practice, and the workplace goals. Therefore, the implementation of the OCC framework necessitated special attention to the design of appropriate pedagogies. It was premised on the notion that learning would be influenced by, and in turn influence, the strategic direction of the organisation. Subsequently, the content needed to be relevant to the organisation - that is fulfil the requirements of both the intended and emergent strategic plans - and at the same time be relevant to the learners, with obvious application to their functional roles. Accordingly, a boutique curriculum was negotiated and packaged with four study units: Leadership for Change; Politics of Diversity and Identity; Managing Knowledge in Organisations; and Changing Agendas in Leadership. These units were designed to develop the leadership capacity of twelve staff from across the different levels. It was expected that the new knowledge and skills gained from the study will assist participants with the implementation and management of projects arising from recent reforms. The content for these units was largely collated by the academics, with some industry specific content (published articles and the NGO's internal documents) pro- 
vided by the managers and learners. The learning strategies for this course needed to suit the learning preferences of the cohort. Here, learning strategies were interpreted as the combination of the learning processes and activities, and the assessment tasks to demonstrate that learning had occurred. The curriculum and delivery arrangements were also deliberated against the university policies, systems and structures.

Driven by their employer's purpose of sponsorship and expectations the learners were interested in immediate application and transfer of knowledge and skills to develop their leadership capacity for managing reforms in the health and community services industry. So, it made sense to treat the workerlearners as a cohort and engage them in work integrated learning. The learning cohort of twelve staff formed a critical mass that collectively participated in sensing, construing, analysing and responding to changes to achieve the strategic goal of their organisation. The worker-learners contextualised what they learned to initiate and also facilitate a gradual change process. In partnership with the academics and coalition with staff across the organisation they collaborated and negotiated the bridge between theory and practice, and created new knowledge that added value to their organisational services and strategic goal. In this way the curriculum met their own as well as the organisational needs.

While the needs of organisation underpinned the program, the learning needs of the individuals arose from and were aligned to these. For instance, for the purpose of assessment they chose projects that they worked on and had relevance across the organisation. Individuals took control and worked collaboratively to resolve any leadership issues.

I wanted to get out of it an opportunity to work across teams within this organisation, to get a broader perspective of the change that was happening to the then ITC [abbreviated former name of the NGO]. (WFC007).

That it took place in that group context so there was a tremendous amount of support and sharing of ideas, and that it was something that was to be part of the workplace and what we do. So I had an opportunity to learn how to work in a continuous improvement environment where I hadn't really experienced that before.... I like to know the broader context in which I'm working and why. (WFC006).

Miller (2003) contends that projects that were of particular interest to individuals also offer more confidence and practicality.

\section{Teaching and assessment strategies}

The learning strategies and the assessment tasks had to be appropriate to achieve the learning objectives, a configuration termed by Biggs (1999) as 'constructive alignment'. For purposes of constructive alignment, Biggs’ (1999) Structure of Observed Learning Outcome (SOLO) model and Delahaye’s (2005) Hierarchy of Learning Outcomes (HLO) were employed. The SOLO model proposes aligning learning strategies and learning outcomes, and describes how a learner's performance grows in complexity when mastering a topic. The HLO provides the designer with two important indicators - the type of content that the learners need to cover and, the most appropriate type of learning strategy that should be used.

Considering the worker-learners had prior academic learning experiences as well as extensive work experiences, the design of the learning activities was founded on three governing values:

(i) The andragogical principles of work centred problems and issues and learning that acknowledged and utilised the work experience of adult learners 
(ii) Overtly situated learning within the strategic directions and cultural context of the host organisation.

(iii) Individual learning embedded within the normal workplace tasks, processes and goals to concurrently achieve learning outcomes and organisational goals as well as develop sustainable knowledge reservoirs.

The goal was to focus on acquiring, improving and transferring knowledge, facilitating and making use of individual learning that would in turn modify behaviours and policies within the organization. So, there were strong aspirations by the cohort for some transformational learning, as described by Mezirow (1991).

\section{Teaching Strategies}

The course was facilitated using a blended approach, comprising internet based delivery and face-toface onsite consultation. The content and structure of the face-to-face consultations with individuals or groups were determined by them. Individuals were required to send requests for specific information or topics/issues to be discussed at least two working days before the session. This allowed the facilitator to adequately prepare for the sessions. The learners in the cohort had various levels of readiness for selfdirected learning. Some had recent academic learning experiences while for others had not participated in any formal academic learning for sometime or worked with staff across their organisation. This became an important consideration when grouping students for team work. Participants with knowledge and skills in the study areas and also academic writing became the local 'champions' and supported their colleagues. The cohort was divided into three teams, each operating as a community of practice. They organised group meetings during work hours, evenings or in the weekends. This type of flexibility suited learners who constantly travelled around the State.

The learning materials were posted on the university's course website, allowing the cohort to access and interact with the materials from their work or home computers, at a time of their own choosing. The online teaching and learning platform (Blackboard) provided access to a range of learning resources, websites and wiki space for interactions. Because the NGO had a well designed information and computer technology (ITC) system the learners chose to use this more frequently than the Blackboard site of the university. They were all acquainted with their onsite ITC system which offered functions comparable to Blackboard and gave the added advantage of interacting and sharing with other staff in their workplace. In this way the use of the local ITC system engaged other staff in informal learning with the cohort and developed a learning culture that remained even after the completion of each unit.

This is helping in the development of a learning organisation culture as this information is also being shared more widely during staff meetings with staff not involved in the study (WFC002).

There is a common language because people mention different theorists and they mention different models so there is a sophisticated way of talking about what we do and helping kind of cluster ideas together (WFC003).

Over the first two semesters they became increasingly motivated as they began to interpret and critically analyse the new knowledge they acquired from the study unit in the context of their work. As they developed new perspectives and gained more self- confidence, they challenged current thinking and work practices through a process of critical reflection and discussions with staff within the organisation. This enabled them to gradually influence changes to the NGOs' systems, policies and practices with aims to improve services. 
I've just looked at certain elements and how their theories can impact upon them. I have created a couple of tools - a number of tools. In particular a couple of procedures around induction have been incorporated very recently into how we bring staff on board as a change process. (WFC006).

Certainly it guided us to rethink about reference group and our workplace plan and network that we had and sort of reshaped those two groups and clearer about their roles and responsibilities. (WFC009).

As an example, the approach to teaching and assessment for the first study unit (Leadership for Change) is described here. The objectives of this unit and those of the learners (based on their work projects) were aligned with organisational objectives that were interpreted from its strategic goal. The unit offered development of expertise in three areas:

- Investigating and Analysing Organisational and Environmental Cultures (Themes = the changing nature of organisations, organisational culture, organisational values).

- Accountability (Themes = ethics, relationship building, accountability and organisational improvement).

- Change Management (Themes = communication, the change process, leading the change process).

The individuals in the cohort self-selected themselves into one of three teams, each focusing on one of the study areas. The use of teams was reinforced by the writings of Knowles (1998), Revans (1988) and Wenger (1998) who emphasise that adult learning is a social process. Each team shared three features: a common domain of knowledge to be developed; a community that cares and takes responsibility for the domain knowledge in the organisation; and shared practice to effectively interpret and apply their domain knowledge. In this way the communities or teams became nodes for exchange and interpretation of their domain knowledge. These features are characteristic of communities of practice (Wenger, 1998). The nodes transpired into a useful knowledge management tool that supported and stimulated learning within the organisation.

The intention of the teams was to develop in-depth knowledge and understanding of their area of study and to explore the diversity of applications across various aspects of their functions. In other words, the learners were expected to operate at the relational level of the SOLO model (Biggs, 2003) so that they would be able to "compare/contrast, explain causes, analyse, relate and apply" (p.48). They researched and updated their knowledge base on developments both internally (within the organisation) and externally (nationally, internationally and beyond their industry). Members of the groups read, summarised and critically analysed the assigned readings and additional articles they sourced. As recommended in the HLO model (Delahaye, 2005), the worker-learners engaged in self-directed learning, experiential learning and problem based learning, thus reinforcing the need for blended learning based on questions initiated by the learners.

The learning strategies involved a three stage process suggested by Garvin (1994):

- A cognitive process to make them think critically and reflectively, be exposed to and share new ideas and knowledge.

- Behavioural change process resulting from the internalization of new knowledge and changes in frames of reference and perspective.

- Effective change and improvement in project outcomes, and subsequently, organizational performance. 
The cohort participated in mutual learning, within communities of practice (teams), to apply new understandings and reflect on workplace issues and problems. The communities of practice engaged with other staff in the organisation and eventually connected the learning with the wider organization. The process resembles what Miller (2003) describes as action learning. The design of the teaching and learning strategies met their pedagogical needs.

I think there was flexibility in peoples different learning styles as well that you - people who learnt more by talking to each other and sharing ideas and that opportunity people who learn by reading and taking in that way had that opportunity. So you know, it meant that the majority of peoples needs were catered for (WFC009).

The process made me aware that you can only really learn so much as an individual, and that group aspect is really crucial to broadening your own understandings and your own comprehension. Certain issues, particularly, as the change management and the culture materials in the first unit were so broad...that conversational style of learning and sharing ideas and it really gets your thinking going in terms of how to relate it to a real world context (WFC006).

The approaches and strategies for learning described above are common practice in traditional university teaching however, have particular significance in the context here and highlight the alignment of university learning to real work outcomes. Traditionally, when such activities are conducted in lecture rooms, the authenticity of alignment and application of knowledge is left to the individual learners. The validity and feasibility is often unverified, mainly because that is an assumed role of the workerlearners.

The success of the strategies described above is partially attributed to a very supportive learning environment within the NGO. The participants were allowed some work time for group meetings/learning; they could use the ITC system; they had access to resources within the worksite; the line managers were available to advice/ give directions; and most other staff were supportive. The fact that the CEO of the NGO was also a learner contributed to a high level of support. The learning process and experiences of the cohort were supported by features of expansive learning environment such as those identified by Fuller and Unwin (2004). For example, learners participated in multiple communities of practice including those external to the organisation (its regional staff, networks and stakeholders). They engaged in diverse tasks, knowledge bases and experiences to encourage a learning culture within their workplace. Their learning was acknowledged, supported and formally valued as organisational capability. Workplace pedagogies, described by Billett (2001), were made available and utilised by the cohort. These pedagogies included questioning and getting explanations, observation and listening, interacting with others, accessing documents in the workplace, and learning from daily work activities through practice. These pedagogies were supported by workplace affordances such as fortnightly team meetings; internal communication systems (oral, written and electronic); time allocation for group learning; opportunities to solve problems; systemic knowledge of the workplace; shared responsibility for learning and achieving organisational goals; and timely access to assistance from others.

\section{Assessment and evaluation}

There were two major assessment tasks for this unit. Each of these tasks needed to demonstrate constructive alignment (Biggs, 1999) and, again, the SOLO model (Biggs, 2003) and the HLO (Delahaye, 2005) proved useful here. A combination of individual and group tasks met the needs of the learners. The assessment tasks were designed to generate deeper learning and required them to state how the ideas could be applied to the functions of the NGO. Regular staff meetings and professional development workshops afforded them with opportunities to share, reflect on, and discuss concepts and ideas with others in the workplace. In this way they retained their knowledge domains in "living" ways and maintained an organisational focus. 
The first task was team based and involved two deliverables (25\% each) - oral seminars and a resource folder. The seminar presentations needed to demonstrate deep analysis and application of theoretical concepts to the work tasks - the relational level of SOLO (Biggs, 2003) and the deeper levels of the Task, Relationship and Critical Thinking categories of the HLO (Delahaye, 2005). After the seminar, each group collated the summaries of the assigned readings and added these to the resource folder. The summaries and analysis from each group were presented in a format allowing the remaining two groups to gain a basic understanding of the themes within the area of study, and also to be able to apply the theories and learning into the context of their work. The three teams served as organisational 'experts' in the three areas (Investigating and Analysing Organisational and Environmental Cultures; Accountability; and Change Management). The resource folders also included tools, websites and other usable materials for other staff in the organisation, their stakeholders and networks. Examples of tools included: definition of key terms, guidelines, theoretical and conceptual frameworks, evaluation items, surveys, checklists, to-do lists, relevant legislations, regulatory frameworks, case study examples and benchmarks.

The second assessment task was completed individually and was based on personal learning objectives based on work projects. It included two aspects: oral seminar and written essay. Individuals were required to work collaboratively. Miller (2003) contends that when learners engage in activities that are of interest and can help solve issues that are important to them, they are able to increase confidence and practicality. Each learner presented a case example that demonstrated the application of their understanding gained from the study unit content. During the seminar there was much discussion around the diversity in the applications and viability of what was proposed in the broader context of the health and community services industry and its stakeholders. Interestingly, the cohort began linking the concepts and ideas beyond the selected projects, to other areas of work in the organisation. This linking took the learners beyond the relational level into the extended abstract level of the SOLO model (Biggs, 2003).

The presentations were assessed by peers and an academic panel who used an evaluation proforma. The peer panels also validated the correct interpretation of the knowledge into the context of the NGO and confirmed the feasibility of changes that were proposed or implemented through the projects. In this instance, the impact of their contributions in terms of organisational outcomes was not only made visible, but also authenticated, differentiating similar presentations in university lecture rooms, where little is known about the impact of what students present. Peer panels were also useful because while the academic panel could assess the applications from a theoretical perspective, as cultural outsiders they were less conversant with the socio-cultural contexts of the NGO or its stakeholders.

The final task for the unit was the submission of individual reflective essays. The evaluation for the first unit not only acknowledged the learners' development in terms of academic recognition of learning outcomes, but beyond this to their development and competence as leaders and change agents in the NGO.

\section{Evaluation of strategies}

At the end of the first unit, the teaching and assessment strategies of the OCC framework was evaluated to examine the benefits and limitations, and to explore potential for use with other units of study and academic courses.

\section{Method}

Data were collected from interviews with ten (of twelve) participants and a focus group of six. A semistructured proforma was used and all, but two conversations were audio taped. Transcripts of each interviewee were coded as WFC 001 - WFC 010. The preliminary findings of the project were presented to a focus group of participants for validation and discussion. 


\section{Findings}

The preliminary outcomes of the first unit are summarised here to draw attention to the results for individuals and their workplaces when teaching and assessment adequately integrates university units with work. The teaching and assessment approaches for an OCC framework contributed to both, individuals as well as the NGO in four main areas: development of knowledge capital, development of skills, cultural change in the workplace, and improvements to organisational systems. The most immediate and greatest change was evident in the new learning culture.

The participants said they particularly liked three aspects of the teaching and assessment strategies: the work integrated learning philosophy; the application of andragogical principles; and the use of a learning cohort.

Work integrated learning philosophy

The benefits of a work integrated learning approach were supported by a number of the participants.

The fact that it was so work based and work placed, so relevant to what I was doing and I guess that the whole organisation was involved. (WFC 007)

The participants provided evidence of learning from the course being embedded into the organisation.

I think that's probably a really good one that people are actually recalling what they've learnt and relating it to what's going on here and trying to share it with other people that are here...(WFC001)

Some of the learners reported specific applications.

And in terms of action in change, relevant to my level at work, I've just looked at certain elements and how the theories can impact upon them. In particular a couple of points have been incorporated very recently into how we bring staff on board as a change process. (WFC005).

These examples demonstrate the strength of work integrated learning and highlight a shift from formal academic pedagogy to workplace pedagogy. The teaching strategies harnessed the potential of workplace pedagogies and affordances of the NGO to embed and embody learning in the context of the organisation and the learners.

\section{Application of andragogical principles}

The design of the program was overtly based on andragogical principles espoused by such writers as Knowles (1998) and Rogers (1983). The learners' comments on this approach were mainly positive, although a few expressed reservations. They appreciated their engagement in decision making and the level of flexibility that allowed the worker-learners to meet multiple goals - academic, organisational and personal.

... I don't think we were looking for them [lecturers] to be an expert. I think we were looking for them to be really a facilitator of our learning patterns. ...I think the way we could negotiate around what the assessment tasks would look like, again was an important component. (WFC 001)

I think the identifying our own learning outcomes and things was a challenge for quite a few people and took them a bit of time (WFC 009) 
These statements demonstrate the value in engaging and empowering learners in ways that meet Knowles' (1998) assumptions of adult learning.

The main concern of two participants related to setting of learning objectives. They demonstrated a preference for a pedagogical approach with which they were most familiar. That is, they expected the academics to set the learning and assessment content and requirements, as in many university units.

...I didn't enjoy doing those objectives at all. I struggled because I guess I'm just used to people giving it to me and just having to work with it and not really questioning it. (WFC 002)

As an individual I found it very challenging. I'd never set my own objectives before. And I really grappled with it for a while. (WFC 006)

The comments above reflect typical approaches where the learning content and assessment is predetermined by the academics. Setting own learning objectives and negotiating assessment need skills sets that not all learners have. A two hour workshop was conducted to assist the cohort. Following this, each learner submitted a draft set of objectives and the academics provided comments. The comments were largely in relation to the wording of the objectives and their scope. Most of the participants found the workshop useful, particularly the skills for developing objectives, their measures and indicators. They explained the usefulness of this when developing their normal work project objectives and establishing specific indicators and outcomes for their suppliers. The feeling of overwhelm when adults first experience andragogy was also noted Rhodes and Shiel (2007). By the second semester, the cohort increasingly engaged in negotiations about the relevant content to be included, nature of their assessment tasks, what and how to achieve these. This demonstrated their rising levels of confidence and comfort with andragogy.

Use of a learning cohort approach

The grouping of the cohort into three teams was a central plank of the design. All but one of the learners stated that she enjoyed this approach.

... it probably pushed people to deliver very quality products ... There was a personal value of what they were doing because of who they were doing it with. (WFC 001)

I loved the fact that I had a work team around me or a learning team around me who brought different skill sets and different perspectives...You know, people just shared everything they had and we found mechanisms to do it and as you know that physical resource now available on PDF for everyone [referring to the resource folder] started to be developed by all of us contributing so that was - I found that quite amazing. (WFC 003)

Finally, there was evidence that the learners had engaged in positive reflection.

The unit's given me the time to look at our processes, so take a step back from my day to day tasks and look at our processes as a whole and then look for opportunities for improvements. So it's been a very good environment in terms of having that reflection time and reflecting upon what you do. (WFC005)

The findings of the evaluation illustrate that the learning and assessment activities were well aligned to the functional roles of the individual learners and the NGO's strategic objective of providing high quality services to the health and community services industry.

\section{Limitations}


At beginning of the study program the academic assumed that the cohort had the skills set necessary for participating in aspects of andragogy. Indeed it was found that the learners had never negotiated their learning program before. They learnt the relevant skills during a workshop.

Although the NGO was generally very supportive of a work integrated learning program, there was a lack of clarity about what was expected of the learners. That is, the nature of affordances was unclear to the worker-learners, as explained by one participant:

... it was never very clear though about how much time you were allowed to take out of your work time and to be honest we always used to meet in work time, but it was still on our time sheet that we were at work...They never said you can only take two hours a week... (WFC 002)

According to Billett (2002) the intentionality of the learners to engage in learning afforded by the workplace is determined by their interpretation of the nature of what is afforded. They then tend to navigate between those affordances and the organisational culture to complete the learning tasks. While the participants were termed "worker-learners", the organisation needed to recognise that they cannot be both at once. Learning will take time away from the usual work-day tasks and require resources and this needed to be negotiated between the individuals and their supervisors or the NGO. Despite this limitation and some confusion in the first semester, the participants received encouraging support from the NGO. Indeed the NGO also experienced a steep learning curve as it was the first time a cohort was sponsored for a university program.

\section{Conclusions}

An OCC framework traversed from a conventional learner-centred to an organisation centred focus to maintain a common goal of learning that served the organisation as well as the learner's functional roles. Here, the strategic objectives of the organisation became the common goal while the individuals remained the agents whose learning outcomes helped achieve the goal. To harmonise a balance between the organisational and individual learning needs, specific teaching and assessment strategies were designed for this case study. These strategies embed and embody learning in the context of the learners and their workplace in ways that optimise benefits for both, the individuals and their organisation. The strategies navigate learning between the disciplines of academia and the workplace.

The findings of the evaluation of an OCC framework for work integrated learning suggests its potential for use of the teaching and assessment strategies for other cohorts participating in work-based learning courses. Notwithstanding the strengths of the teaching and assessment strategies described in this paper, it is important to skill learners for work integrated learning and make explicit the pedagogies and affordances available in the workplace. Only then will learning from an OCC result in optimum outcomes for the learners and their organisations.

\section{Acknowledgement}

The support and contributions of various staff from the faculty of education at the Queensland University of Technology is duly acknowledged. Participation in the interviews and focus group by the Executive Director, liaison person and members of the cohort from the NGO is also appreciated.

\section{References}

Biggs, J.B. (1999), Teaching for quality at university: What the student does, Buckingham, Open University Press, UK.

Biggs, J.B. (2003), Teaching for quality learning at university $\left(2^{\text {nd }}\right.$ ed.), Open University Press, Maidenhead, UK.

Billett, S. (2001), Learning in the workplace: Strategies for Effective Practice, Allen \& Unwin, Crows Nest. 
Billett, S. and Boud, D. (2001), "Participation in and guided engagement at work: Workplace pedagogic practices”, Paper presented at Researching Work and Learning, Second international conference on learning and work, Calgary, Alberta, 26-28 July.

Boud, D. and Solomon, N. (eds.) 2001, Work-based learning, OUP, Oxford.

Brodie, P. \& Irving, K. (2007), “Assessment in work-based learning: investigating a pedagogical approach to enhance student learning”, Assessment \& Evaluation in Higher Education, vol. 32 no.1, pp. 11-19.

Brown, B. L. (1998), “Applying constructivism in vocational and career education”, Information Series No. 378, Columbus: ERIC Clearinghouse on Adult, Career, and Vocational Education, Center on Education and Training for Employment, College of Education, The Ohio State University, (Eric Document Reproduction Service No. ED428298), http://cete.org/acve/majorpubs.asp

Bryson, J., Pajo, K., Ward, R., and Mallon, M. (2006), "Learning at work: organisational affordances and individual engagement”, Journal of Workplace Learning, vol. 18 no. 5, pp. 279-297.

Cameron, K.S. and Quinn, R.E. (1999), Diagnosing and changing organizational culture, AddisonWesley, Reading.

Delahaye, B.L. (2005), Human resource development: Adult learning and knowledge management ( $2^{\text {nd }}$ ed.), John Wiley \& Sons, Brisbane, Australia.

Fuller, A. and Unwin, L. (2004), "Expansive learning environments: integrating organisational and personal development”, in Rainbird, H., Fuller, A. and Munro, A. (eds.), Workplace Learning in Context, Routledge, London, pp. 126-44.

Garvin, D. (1994), “Building a learning organisation”, Business Credit, vol. 96 no. 1, pp. 19-28.

Knowles, M.S. (1998), The adult learner: A neglected species ( $5^{\text {th }}$ ed.), Gulf, Houston, Texas.

Mezirow, J. (1991), Transformative dimensions of adult learning, Jossey-Bass, San Francisco.

Miller, P. (2003), "Workplace learning by action learning: a practical example”, Journal of Workplace Learning, vol. 15 no. 1, pp. 14-23.

Revans, R.W. (1988), The ABC of action learning, Chartwell-Bratt, Kent, UK.

Rhodes, G. and Shiel, G. (2007), "Meeting the needs of the workplace and the learner through workbased learning”, Journal of Workplace Learning, vol. 19 no. 3, pp.173-187.

Rogers, C.R. (1983), Freedom to learn for the 80s, Charles E. Merrill Publishing Company, Columbus, Ohio.

Sobiechowska, P. and Maish, M. (2006), "Work-based learning: in search of an effective model”, Journal of Educational Action Research, vol. 14 no. 2, pp. 267-86.

Symes, C. \& McIntyre, J. (2000), «Working knowledge: An introduction to the new business of learning”, In Symes, C. \& McIntyre (2000) (eds.), Working Knowledge: The new vocationalism and higher education, SRHE and Open University Press, England, pp. 1-14.

Wenger, E. (1998), Communities of practice: Learning, meaning, and identity, Cambridge University Press, Cambridge. 